\title{
INFECÇÃO PIÓGENA DO ESPAÇO EPIDURAL RAQUIDIANO EM CRIANÇA
}

\author{
ANTONIO B. LEFÈVRE * \\ Aron J. Diament **
}

A infecção piógena do espaço epidural é condição clínica rara, mas suficientemente bem descrita e reconhecida. Nos Estados Unidos da América do Norte foram feitas excelentes revisōes, notadamente por Dandy, Browder e Meyers, Rankin e Flothow, Huesner. Dandy em 1926 encontrou 25 casos registrados na literatura, ao passo que Rankin e Flothow, em 1946, reviram 225 casos. Em nosso meio ${ }^{2}$ recentemente foi relatado um caso com tratamento clínico satisfatório. $\mathrm{O}$ atual registro se justifica pelo satisfatório resultado do tratamento e pelos elementos em que foi baseado o diagnóstico.

V. M. S., 7 anos de idade, sexo feminino, branca, internada a 6-2-59 (Reg. Geral 345.361). Fm 20 janeiro 1959 a paciente sofreu uma queda, caindo sôbre a região glútea; nada sentiu nos dois dias seguintes; depois, passou a se queixar de dor na nádega esquerda, sem estar afebril; as dôres se tornaram progressivamente mais intensas e, em 24 Janeiro, já se estendiam a todo o quadril e ao membro superior esquerdo; neste dia a paciente amanheceu febril; tornou-se, então, progressivamente apática; a fôrça muscular diminuiu nos quatro membros, mals intensamente nos membros inferiores e não mais deambulou. Em 1 fevereiro a paciente fol encaminhada ao Pronto Socorro do Hospital das Clinicas, onde fol feita punção lombar sendo obtidos apenas $2 \mathrm{ml}$ de material purulento. Nos antecedentes consta que a menina apresentou lesōes cutâneas (descritas como feridas purulentas e crostosas) um ano antes da moléstia atual; tais lesões, que haviam sarado, reapareceram nas pernas um mês antes do inicio da sintomatologỉa atual.

Internada inicialmente na Clínica de Moléstias Infecciosas, a paciente apresentava estado geral regular, prostrada, sendo dolorosa a mobilização. $O$ exame neurológico mostrou: psiquismo integro, tetraparesia motora desproporcionada, mais intensa nos membros inferiores e no membro superior esquerdo, de tipo tlácido, sem Babinski ou outros sinais de libertaçāo; todos os reflexos profundos abolidos; anestesia tátil e dolorosa nas faces ântero-laterais da coxa esquerda e lateral da perna do mesmo lado; incontinéncia de esfincteres. Neste dia foram realizados os seguintes exames: 1) exame otorrinolaringológico normal; 2) hemossedimentacão $52 \mathrm{~mm}$ na 10 hora (normal $12 \mathrm{~mm}$ ); 3) Hemograma: leucocitose, neutrifilia, desvio à esquerda; 4) exame bacterioscópico do material obtido na punçāo lombar, grande quantidade de Micrococcus, o que foi confirmado pela cultura do material. No dia 2-2 foi notada rigidez de nuca que perdurou apenas por êste dia. A 3-2 o quadro motor estava inalterado e o nivel da sensibilldade já atíngla a linha mamilar (fig. 1). Suspeitada a existência de meningomielite ou infecção piógena do espaço epidural

Trabalho da Clinica Neurológica da Fac. Med. da Univ. de São Paulo (Prof. Adherbal Tolosa), apresentado ao Departamento de Neuro-Psiquiatria da Associaçāo Paulista de Medicina em 5 maio 1959. *Docente livre. ** Assistente voluntário. 
foram feitas punçōes raquidianas combinadas: o liqüido cefalorraquidiano colhido por via suboccipital foi normal ao passo que o material obtido por via lombar $\left(\mathrm{L}_{4}-\mathrm{L}_{\mathrm{i}}\right)$ apresentou-se limpido e xantocrômico, com 48 células por $\mathrm{mm}^{3}, 650 \mathrm{mg} / 100 \mathrm{ml}$ de proteinas, reação de Pandy positiva; a prova de Stookey revelou bloqueio completo do canal raquidiano.
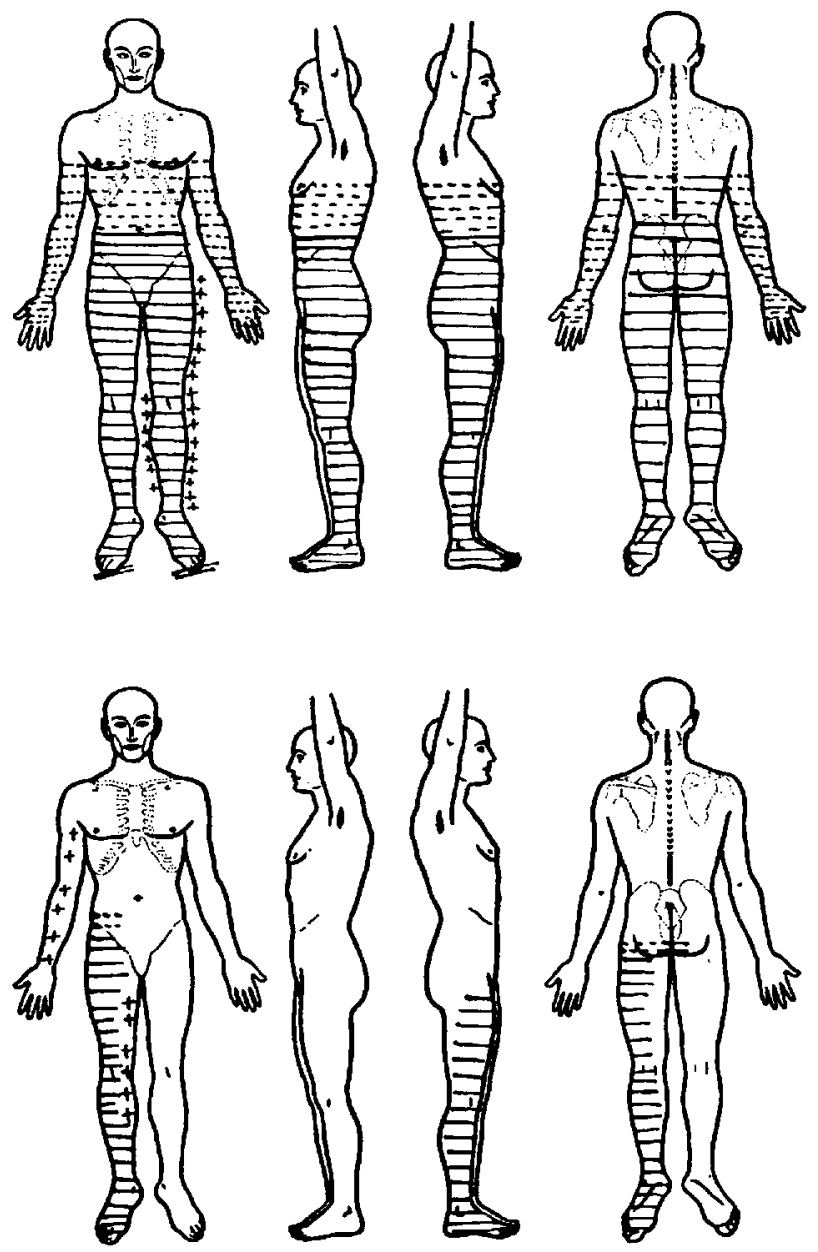

Fig. 1 - Caso V. M. S. Gráficos dos distúrbios sensitivos. Na parte superior, exame feito em 6-2-59; na parte inferior, exame feito em 13-2-59. Legenda: hipoestesia superficial (tracos interrompidos), anestesia superficial (tracos cheios), hipoestesia dolorosa (cruzes), abolição da sensibilidade segmentar (dois traços paralelos).

Em face da evolução e do quadro liquórico mostrado pelas punções combinadas, firmou-se a suspeita de infecşáo piógena do espaço epidural, sendo a paciente trans- 
ferida para a Clinica Ncurológica a 6-2, cnde foi feito espondilograma que se mostrou normal; a seguir col feita perimielografia descendente que mostrou progressão lenta do contraste e diminuição das diâmetros do cilindro dural, compativel com a existência de constrição do espaço subaracnóideo por processo extradural difuso (fig. 2). Em virtude da extensão do processo (da regiāo cervical à lombar) foi contraindicada a intervenção cirúrgica, sendo feita medicação antibiótica intensa, associada à administração de glicocorticóides por via oral (Cloromicetina, via oral, 2 g/dia; Penicilina aquosa, via intramuscular, 4 milhōcs/dia; Omcilon, via oral, $4 \mathrm{mg} / 6$ horas).
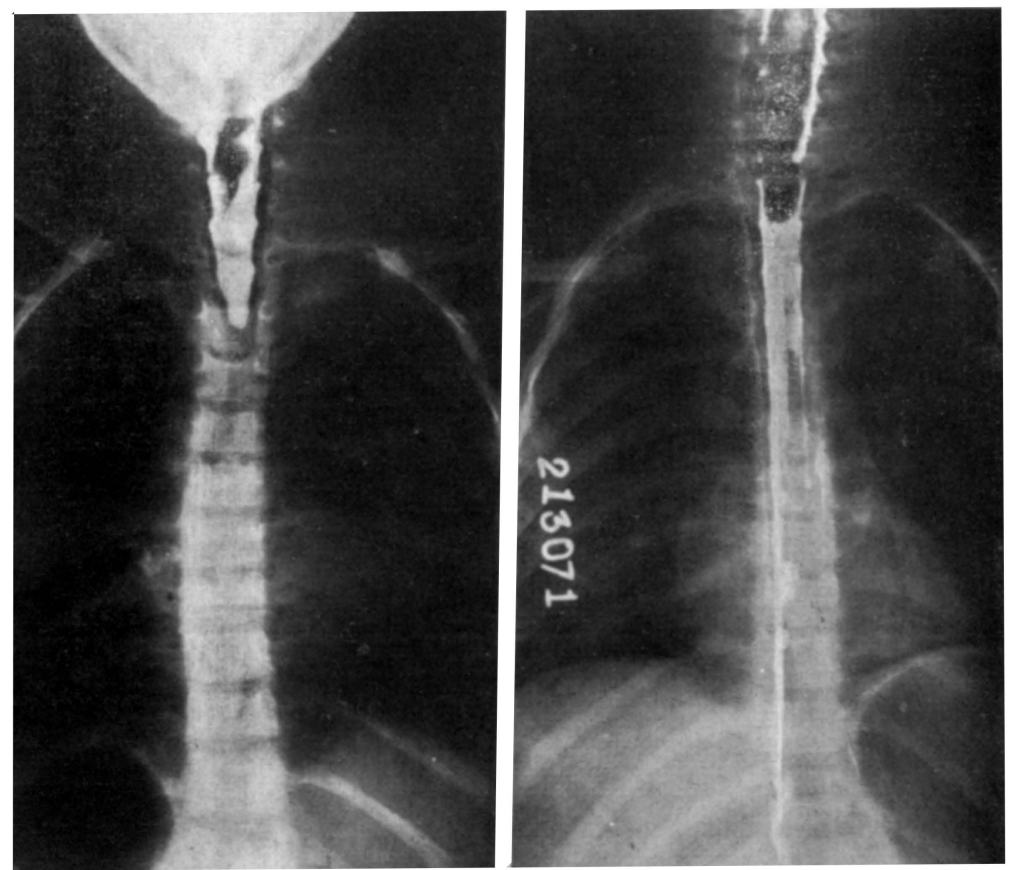

Fig. 2 - Caso V. M. S. Perimielografia: à esquerda, contraste na regiōo cervical em progressão lenta; à direita, diminuicão dos diametros do cilindro dural.

A evolucão foi satisfatória: no decorrer de uma semana, o quadro de paralisia flácida se modificou com o aparecimento de sinais de libertação, tornando-se espástico; a paciente passou a movimentar progressivamente os vários segmentos (artelhos, membro inferior esquerdo e dedos das mãos), e a sensibilidade regrediu, permanecendo apenas zona de hipoestesia superficial na face ântero-lateral e posterior do membro inferior direito (fig. 1). Em 26-2 a pacjente já realizava movimentos mais amplos com os membros, as dóres à mobilizaçāo já haviam desaparecido e a sensibilidade objetiva era normal. Nessa ocasiāo foi tentada inùtilmente punção do espaco epidural. O exame do liqüido cefalorraquidiano, colhido por via lombar em 6-3-59, resultou normal. Por ocasiāo da alta, em 23 março, os membros superiores estavam íntegros quanto à motricidade e a paciente já andava apoiada e controlava bem os esfincteres. 


\section{COMENTARIOS}

O interêsse maior do registro dêste caso reside nas peculiaridades que o mesmo apresentou no início, levando a um falso diagnóstico de meningite purulenta. Com efeito um quadro infeccioso agudo com sinais de irritação meníngea, no qual uma punção lombar deu saida a um líqüido purulento levaria àquele diagnóstico. Vimos que em nosso caso depois dêste diagnóstico inicial fomos levados a pensar em infecção do espaço epidural pelos motivos que exporemos abaixo.

Nas epidurites a fonte da infecção varia de um caso para outro, podendo ser próxima (contigüidade ou continuidade) ou à distância (via sangüinea). Em nosso caso, a paciente apresentara, um antes antes da moléstia atual, uma infeç̧ão da pele, que reapareceu um mês antes do inicio da sintomatologia neurológica. Em trabalho de revisão Hulme e Norman ${ }^{1}$ verificaram que a fonte de infecção mais comum fôra a supuração cutânea ou subcutânea $\left(8 / 25\right.$ casos). Um de nós ${ }^{2}$, recentemente publicou um caso de infecção piógena do espaço extradural raquidiano com foco primário à distância (osteomielite mandibular). No presente caso a fonte foi a infecção da pele; o acometimento do espaço epidural talvez tenha sido desencadeado pela queda que a paciente sofrera dois dias antes do início da sintomatologia neurológica. Os autores acima referidos já haviam acentuado a importância de fatôres precipitantes, principalmente traumatismos da coluna vertebral.

Os elementos importantes para o diagnóstico de infecção piógena do espaço extradural são, como se infere dos elementos de nossa observação: 1) limitação da sintomatologia subordinada ao acometimento exclusivo das estruturas contidas no canal raquidiano, sem manifestação de comprometimento cerebral; 2) os dados fornecidos pelas punções raquidianas combinadas - suboccipital e lombar - tendo-se em conta que muitas vêzes a punção na região lombar pode fornecer resultados enganadores pela retirada de material purulento do espaço epidural, como ocorreu na primeira punção lombar praticada no caso aqui relatado.

O tratamento da infecção piógena do espaço epidural está na dependência de sua forma clínica, sendo melhor o prognóstico quando a infecção é tratada na fase aguda; na estatística de Hulme e Norman ${ }^{1}$, em $4 / 13$ casos tratados na fase aguda houve completa recuperação; esta foi menor nos casos tratados em fases subagudas e crônicas. A indicação cirúrgica era obrigatória antes do advento da terapêutica antibiótica. Alguns autores continuam insistindo na indicação da intervenção cirúrgica, mesmo nas formas agudas; entretanto, a evolução favorável do caso aqui relatado e de outro anteriormente registrado ${ }^{2}$, demonstra a eficácia da terapêutica pelos antibióticos nas fases agudas de epidurites infecciosas. Além disso, em nosso caso, a extensão do processo (da coluna cervical à lombar) tornaria inviável a intervenção cirúrgica. 
RESUMO

Registro de um caso de infecção piógena do espaço epidural raquidiano, provàvelmente originada de lesão purulenta da pele, o inicio da sintomatologia ocorrendo após traumatismo da coluna vertebral. Os autores acentuam a importância dos seguintes fatos para o diagnóstico: 1) sintomatologia neurológica limitada à lesão das estruturas contidas no canal raquidiano; 2) as diferenças citoquímicas do líqüido cefalorraquidiano colhido em punções combinadas, suboccipital e lombar; 3) os resultados da mielografia mostrando a lentidão do trânsito da substância contrastante. O tratamento clínico, à base de antibióticos em doses intensas e glicocorticóides por via oral, deu excelentes resultados, demonstrando que, nesses casos agudos, o tratamento conservador deve ser preferido à intervenção cirúrgica.

\section{SUMMARY}

Pyogenic infection of the spinal epidural space in children.

A case of purulent infection of spinal epidural space is reported. A pyodermitis was the infection's origin and the onset of the neurologic symptoms was coincident with a spinal trauma. For diagnostic purposes, the authors call attention to: 1) neurologic symptomatology indicating damage of structures contained in the vertebral canal; 2) citochemical differences verified by simultaneous examination of suboccipital and lumbar cerebrospinal fluids; 3) slow contrast progress showed by mielography. The treatment with antibiotics and glicocorticoids was successfull. Clinical treatment of epiduritis at the acute stage is recommended.

\section{REFERENCIAS}

1. HULME, A.; DOTT, N. M. - Spinal epidural abscess. Brit. Med. J., 1:64-68 (janeiro, 9) 1954. 2. LEFEVRE, A. B.; BEDIA, M. L. - Infeccão do espaço epidural raquidiano. Arq. Neuro-Psiquiat., 17:57-60 (marco) 1959.

Clinica Neurológica - Hospital das Clinicas da Fac. Med. da Univ. de Săo Paulo - Caixa Postal 3461 - São Paulo, Brasil. 